Original Article

\title{
Changes in hip and spine movement with increasing running speed
}

\author{
Michio Tojima, PhD, PT ${ }^{1,2)^{*}}$, Ayaka Osada, BSc ${ }^{3)}$, Suguru Torit, PhD, MD ${ }^{4)}$ \\ 1) Tokyo International University: 2509 Matoba, Kawagoe, Saitama 350-1198, Japan \\ 2) Waseda Institute for Sport Sciences, Japan \\ 3) School of Sport Sciences, Waseda University, Japan \\ 4) Faculty of Sport Sciences, Waseda University, Japan
}

\begin{abstract}
Purpose] We aimed to clarify and compare the changes in thoracic and lumbar spine motion and to elucidate the relationship between hip and lumbar spine motion during running. [Participants and Methods] Seven healthy females were recruited in this study. Hip and spine movement were measured using a 3D motion analysis system when running at 6,9 , and $12 \mathrm{~km} / \mathrm{h}$. One-way analysis of variance was used to compare the changes in hip joint and spine angles during running. Correlation coefficient analysis was used to determine the relationship between the hip and lumbar spine angles at right and left toe-offs. [Results] As the running speed increased, the rotation angles of the thoracic and lumbar spine and the extension angles of the lumbar spine and hip joint significantly increased in the late stance phase. Significant positive relationships were observed between hip flexion and lumbar spine extension angles at toe-off when running at 6 and $9 \mathrm{~km} / \mathrm{h}$ but not when running at $12 \mathrm{~km} / \mathrm{h}$. [Conclusion] To increase the running speed, participants increased the rotation angle of spine and the extension angles of the hip joint and lumbar spine during the stance phase. Participants extended the lumbar spine to compensate for the restricted hip motion at toe-off, which could cause stress to the lumbar spine.

Key words: Running, Spine, Hip joint
\end{abstract}

(This article was submitted Apr. 3, 2019, and was accepted May 27, 2019)

\section{INTRODUCTION}

When people begin running, the spine rotates appropriately. There has been some research on lumbar spine motion from the 12th thoracic vertebra (T12) to the pelvis during running in healthy participants using 3D motion analysis ${ }^{1-3)}$. Schache et al. studied the motion of the lumbar spine in participants aged approximately 30 years during running at $14.0^{3}$ and $14.4 \mathrm{~km} /$ $\mathrm{h}^{2)}$. Saunders et al. measured participants' lumbar spines at running speeds of $7.2-18.0 \mathrm{~km} / \mathrm{h}^{1)}$. Rendos et al. measured pelvic and trunk motion during running in 25 year-old male and female triathletes ${ }^{4}$.

Some elite runners experience low back pain, such as spondylolysis ${ }^{5)}$. Low back pain is caused by hip-spine incoordination during movement ${ }^{6)}$ and repetition of excessive lumbar extension and rotation ${ }^{7)}$. However, there have been no reports on the relationship between hip and lumbar spine motion nor have there been studies comparing spine motion in healthy females at different running speeds.

It seems prudent that a better understanding of changes in thoracic and lumbar spine motion during running is achieved. Clarifying this change in spine motion as well as the relationship of the motion between the hip and lumbar spine in runners could be useful in preventing low back pain. In this study, we aimed to clarify and compare changes in thoracic and lumbar spine motion and to elucidate the relationship between the motion of the hip and lumbar spine during running at three different speeds. It was hypothesized that an increase in spine motion, compensation for a restriction in hip motion, would occur proportionately with increasing running speed.

*Corresponding author. Michio Tojima (E-mail: mtojima@tiu.ac.jp)

(C2019 The Society of Physical Therapy Science. Published by IPEC Inc.

(c) $(-)$ This is an open-access article distributed under the terms of the Creative Commons Attribution Non-Commercial No DerivaCC BY NC ND tives (by-nc-nd) License. (CC-BY-NC-ND 4.0: https://creativecommons.org/licenses/by-nc-nd/4.0/) 


\section{PARTICIPANTS AND METHODS}

This study was approved by the Office of Research Ethics, Waseda University (No. 2016-098). Seven healthy females on the college track team (age, $19.4 \pm 1.4$ years; height, $159.0 \pm 5.7 \mathrm{~cm}$; body mass, $47.8 \pm 4.1 \mathrm{~kg}$; and body mass index, $18.8 \pm 0.5 \mathrm{~kg} / \mathrm{m}^{2}$ ) were recruited in this study. Inclusion criteria require that participants have no history of spine/lower-limb surgeries or painful joints in the lower extremities. All participants provided informed consent. The participants attended regular track and field practice before and after classes and on weekends; training was supervised by their team coaches.

After a 3-min warm up, the participants' clothing and back surfaces were immobilized with a bilateral tape, and 68 spherical markers were placed on each anatomical landmark (Fig. 1). A combination of three marker placements were used: Helen Hayes marker ${ }^{8)}$ for the whole body, Point Cluster Technique ${ }^{9,}$ 10) for lower legs, and a previously described technique for the spine ${ }^{6,11)}$. Based on previously described spine measurement methodology ${ }^{6,11}$, eight original spherical markers were placed on the following anatomical landmarks: the right and left paravertebral muscles at the T11, T10, and T12 to represent a thoracolumbar segment and the right and left paravertebral muscles at the T1, T2, and seventh cervical vertebra (C7) to represent an upper thoracic segment. Real-time running motion was measured using a 3D motion capture system (Qualisys Track Manager, Qualisys AB, Göteborg, Sweden) with eight cameras at $250 \mathrm{~Hz}$ to measure the position of the spherical markers. After the participants became accustomed to running on the treadmill (IGNIO R-16S, Alpen Co., Ltd., Aichi, Japan), they were instructed to run on the treadmill at 6,9 , and $12 \mathrm{~km} / \mathrm{h}$.

Noise was filtered from raw data using a 6-Hz low-pass filter. Biomechanics analysis software Visual3D, version 5 (CMotion, Inc., Germantown, MD, USA), was used for calculating the angle between the thoracic and lumbar spine ${ }^{6}$. The lumbar spine angle was calculated from the thoracolumbar segment with respect to the pelvic segment (the sum of L1-5 vertebral movements), and the thoracic spine angle was calculated from the upper thoracic segment with respect to the thoracolumbar segment (the sum of T3-9 vertebral movements). The spine range of motion was calculated from minimum to maximum spine angle. Previous studies have found that skin movement artifacts from pelvic ${ }^{12)}$ and spinal markers ${ }^{13)}$ are not major sources of error in thin participants. The measurement of spine motion with this method is sufficiently repeatable and reliable ${ }^{11)}$.

Data for the following four events were collected: right foot contact, right toe-off, left foot contact, and left toe-off. The time from one right foot contact to the next right foot contact was recorded for each participant. Data of 10 cycles for each participant were averaged to obtain data for one cycle, and then, this one-cycle data was converted into a percentage.

Statistical analysis was performed using IBM SPSS Statistics version 19.0 (IBM Corp., Endicott, NY, USA). A one-way analysis of variance was used with the Bonferroni post hoc test for comparing changes in the hip and spine angle and time parameters during running. The Pearson product-moment correlation coefficient was used for testing the relationship between hip joint angle and lumbar spine angle at right and left toe-offs. The level of significance was set at $\mathrm{p}<0.05$.

\section{RESULTS}

As the running speed increased, participants significantly shortened the percent time in the stance phase $(\mathrm{p}<0.05$, Table 1$)$. As the running speed increased, the lateral bending and rotation angle of thoracic spine significantly increased $(p<0.05$, Table 2). The participants were found to bend the thoracic spine to the left and rotate it to the left during the right stance phase and vice versa during the left stance phase (Fig. 2A-C). Significant increases in the extension and rotation angles of lumbar spine ( $<<0.01$, Table 3 ) were also observed. It was observed that the participants rotate the lumbar spine to the left and extend it during the late right stance phase and vice versa during the late left stance phase (Fig. 2D-F).

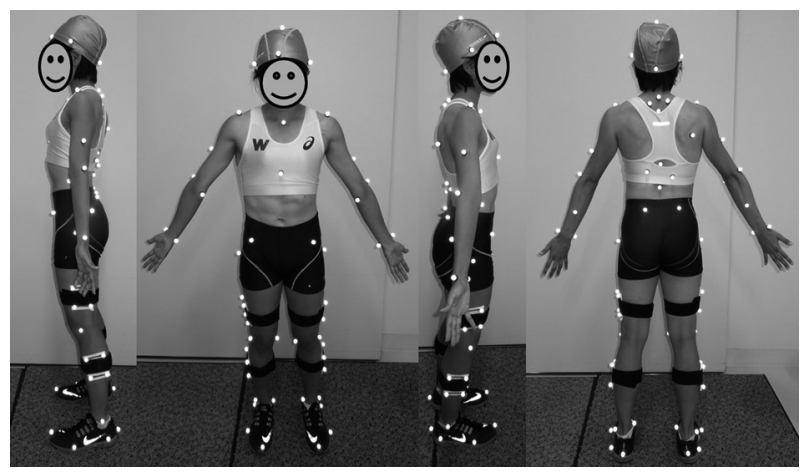

Fig. 1. Location of 68 reflective markers on the whole body of a female runner 
Table 1. Change in time parameters (\%) of each step event during running at three different speeds

\begin{tabular}{llccc}
\hline & & $6 \mathrm{~km} / \mathrm{h}$ & $9 \mathrm{~km} / \mathrm{h}$ & $12 \mathrm{~km} / \mathrm{h}$ \\
& Mean $\pm \mathrm{SD}$ & Mean $\pm \mathrm{SD}$ & Mean $\pm \mathrm{SD}$ \\
\hline \multirow{3}{*}{ Stance phase } & Right* & $43.2 \pm 5.7$ & $35.4 \pm 6.0$ & $33.5 \pm 5.1$ \\
& Left* & $41.6 \pm 3.9$ & $34.5 \pm 4.1$ & $32.6 \pm 5.5$ \\
& Both* & $84.8 \pm 7.9$ & $69.8 \pm 8.5$ & $66.1 \pm 8.0$ \\
\hline \multirow{5}{*}{ Swing phase } & Right* & $7.7 \pm 5.0$ & $15.9 \pm 3.8$ & $15.9 \pm 7.1$ \\
& Left* & $7.5 \pm 3.7$ & $14.3 \pm 5.1$ & $18.0 \pm 4.0$ \\
& Both* & $15.2 \pm 7.9$ & $30.2 \pm 8.5$ & $33.9 \pm 8.0$ \\
\hline Right toe-off* & & $43.2 \pm 5.7$ & $35.4 \pm 6.0$ & $33.5 \pm 5.1$ \\
Left foot contact & $50.8 \pm 1.5$ & $51.3 \pm 3.0$ & $49.5 \pm 6.4$ \\
Left toe-off* & $92.5 \pm 3.7$ & $85.7 \pm 5.1$ & $82.0 \pm 4.0$ \\
\hline
\end{tabular}

$* \mathrm{p}<0.05$.

The $0 \%$ time denotes the right foot contact and the $100 \%$ time denotes the next right foot contact.

Table 2. Change in thoracic spine angle (in degree) during running at three different speeds

\begin{tabular}{|c|c|c|c|c|}
\hline & & $\begin{array}{c}6 \mathrm{~km} / \mathrm{h} \\
\text { Mean } \pm \mathrm{SD}\end{array}$ & $\begin{array}{c}9 \mathrm{~km} / \mathrm{h} \\
\text { Mean } \pm \mathrm{SD}\end{array}$ & $\begin{array}{c}12 \mathrm{~km} / \mathrm{h} \\
\text { Mean } \pm \mathrm{SD}\end{array}$ \\
\hline \multirow{3}{*}{ Flex/Ext } & RoM & $7.5 \pm 5.1$ & $8.5 \pm 7.5$ & $9.5 \pm 8.1$ \\
\hline & Ext & $0.9 \pm 7.6$ & $2.8 \pm 8.3$ & $3.0 \pm 10.0$ \\
\hline & Flex & $-6.6 \pm 5.6$ & $-5.7 \pm 4.6$ & $-6.5 \pm 5.8$ \\
\hline \multirow{3}{*}{ Lateral bend } & RoM* & $4.6 \pm 3.7$ & $5.4 \pm 3.2$ & $6.2 \pm 3.3$ \\
\hline & Left* & $-2.2 \pm 2.7$ & $-3.1 \pm 2.3$ & $-3.7 \pm 3.1$ \\
\hline & Right & $2.3 \pm 3.8$ & $2.3 \pm 3.3$ & $2.5 \pm 3.8$ \\
\hline \multirow{3}{*}{ Rotation } & RoM* & $6.5 \pm 3.9$ & $8.0 \pm 4.2$ & $8.7 \pm 4.1$ \\
\hline & Left & $1.9 \pm 2.7$ & $2.7 \pm 2.2$ & $3.0 \pm 2.0$ \\
\hline & Right & $-4.6 \pm 3.1$ & $-5.3 \pm 3.5$ & $-5.7 \pm 3.2$ \\
\hline
\end{tabular}

$* \mathrm{p}<0.05$; Ext: extension; Flex: flexion; RoM: range of motion.

Increase in absolute value for the negative values denotes increasing angles of flexion, lateral bending to the left, and rotation to the right, respectively.
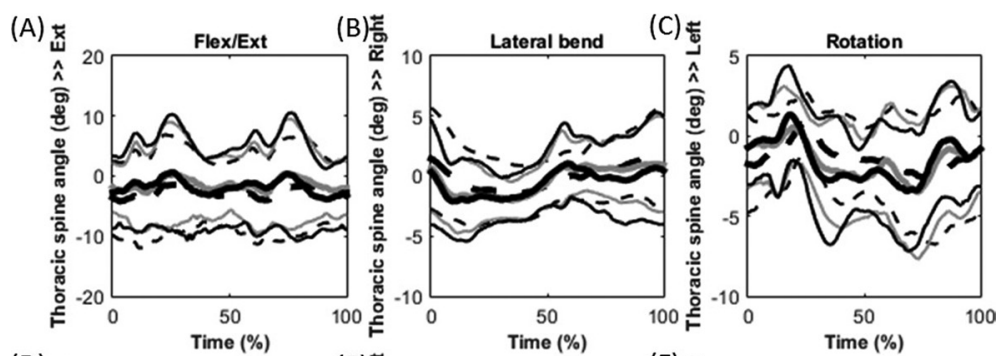

(D)
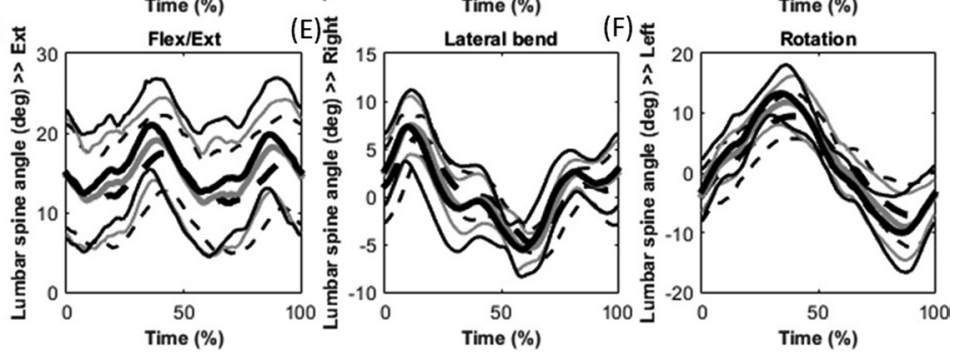

Fig. 2. Mean (thick lines) and SD (thin lines) of the thoracic (A, B, and C) and lumbar spine (D, E, and $\mathrm{F}$ ) angle during running.

Broken lines: $6 \mathrm{~km} / \mathrm{h}$; gray lines: $9 \mathrm{~km} / \mathrm{h}$; black lines: $12 \mathrm{~km} / \mathrm{h}$; Ext: extension; Flex: flexion. The time of $0 \%$ and $100 \%$ denote the right foot contact and the next right foot contact respectively. 
Table 3. Changes in the lumbar spine angle (in degree) during running in the current study vs. those in other reports

\begin{tabular}{|c|c|c|c|c|c|c|c|c|}
\hline & & \multirow{2}{*}{$6 \mathrm{~km} / \mathrm{h}$} & \multirow{2}{*}{$9 \mathrm{~km} / \mathrm{h}$} & \multirow{2}{*}{$12 \mathrm{~km} / \mathrm{h}$} & \multicolumn{2}{|c|}{ Schache et al. } & \multicolumn{2}{|c|}{ Saunders et al. ${ }^{1)}$} \\
\hline & & & & & $14.0 \mathrm{~km} / \mathrm{h}^{3)}$ & $14.4 \mathrm{~km} / \mathrm{h}^{2)}$ & $7.2 \mathrm{~km} / \mathrm{h}$ & $18.0 \mathrm{~km} / \mathrm{h}$ \\
\hline & & Mean \pm SD & Mean \pm SD & Mean \pm SD & $11 \mathrm{~m}, 3 \mathrm{f}$ & $20 \mathrm{~m}$ & & $1 \mathrm{f}$ \\
\hline \multirow{3}{*}{ Flex/Ext } & $\mathrm{RoM}^{*}$ & $8.7 \pm 3.6$ & $10.8 \pm 4.6$ & $11.6 \pm 4.8$ & 15 & 13 & - & - \\
\hline & Ext* & $18.3 \pm 5.4$ & $20.3 \pm 5.4$ & $22.4 \pm 6.1$ & & & & \\
\hline & Flex & $9.6 \pm 5.8$ & $9.6 \pm 6.4$ & $10.7 \pm 7.4$ & & & & \\
\hline \multirow{3}{*}{$\begin{array}{l}\text { Lateral } \\
\text { bend }\end{array}$} & $\operatorname{RoM}^{\Delta}$ & $12.5 \pm 2.9$ & $14.0 \pm 3.5$ & $14.8 \pm 4.4$ & 23 & 19 & 8 & 14 \\
\hline & $\operatorname{Left}^{\Delta}$ & $-5.4 \pm 1.4$ & $-6.1 \pm 1.9$ & $-6.5 \pm 2.0$ & & & & \\
\hline & Right & $7.1 \pm 2.7$ & $7.9 \pm 3.1$ & $8.3 \pm 3.7$ & & & & \\
\hline \multirow{3}{*}{ Rotation } & $\operatorname{RoM}^{*}$ & $17.6 \pm 6.9$ & $21.4 \pm 8.4$ & $24.7 \pm 9.1$ & 24 & 23 & 10 & 19 \\
\hline & Left* & $9.9 \pm 3.8$ & $12.1 \pm 4.5$ & $13.8 \pm 4.7$ & & & & \\
\hline & Right* & $-7.7 \pm 5.3$ & $-9.3 \pm 5.6$ & $-10.9 \pm 5.9$ & & & & \\
\hline
\end{tabular}

${ }^{*} \mathrm{p}<0.05 ;{ }^{\Delta} \mathrm{p}<0.10$; Flex: flexion; Ext: extension; RoM: range of motion; m: male; and f: female.

Increase in absolute value for the negative values denotes increasing angles of flexion, lateral bending to the left, and rotation to the right, respectively.

As the running speed increased from 6 to 9 and $12 \mathrm{~km} / \mathrm{h}$, the right and left hip flexion angles significantly decreased from $15.9^{\circ} \pm 5.8^{\circ}$ to $9.3^{\circ} \pm 6.0^{\circ}$ and $6.5^{\circ} \pm 5.0^{\circ}$, respectively, at toe-off $[F(2,26)=84.367, \mathrm{p}<0.001]$. Significant positive relationships were observed between hip flexion and lumbar spine extension angles at toe-off when running at $6(r=0.70, \mathrm{p}=0.005)$ and $9 \mathrm{~km} / \mathrm{h}(r=0.57, \mathrm{p}=0.035)]$ but not when running at $12 \mathrm{~km} / \mathrm{h}(r=0.57, \mathrm{p}=0.165)$.

\section{DISCUSSION}

An increase in the running speed was compensated by an increase in the extension angles of thoracic and lumbar spine as well as an increase in the rotation angle of lumbar spine during the stance phase. The results of this study are comparable with those of other reports on motion analysis during running ${ }^{1-4)}$. In a previous study, participants extended the spine by $14^{\circ}$ and tilted the pelvis anteriorly by $20^{\circ}$ during running ${ }^{4)}$. Schache et al. reported that when participants ran at $14.0^{3)}$ and $14.4 \mathrm{~km} / \mathrm{h}^{2}$, the lumbar spine was extended by $15^{\circ}$ and $13^{\circ}$, laterally bent by $23^{\circ}$ and $19^{\circ}$, and rotated by $24^{\circ}$ and $23^{\circ}$, respectively. Saunders et al. reported that when the running speed was changed from 7.2 to $18.0 \mathrm{~km} / \mathrm{h}$, participants' lumbar motion changed from $8^{\circ}$ to $14^{\circ}$ for lateral bending and from $10^{\circ}$ to $19^{\circ}$ for rotation ${ }^{1)}$. It has been reported that the runners incline the pelvis anteriorly, extend the spine ${ }^{4)}$, and rotate the lumbar spine ${ }^{1)}$ to increase the running speed. Differences in marker location and running speed may have caused inconsistencies in spine angles between the results of this study and those previously reported ${ }^{1-4)}$. However, there have been no reports on comparing spine motion in healthy females at different running speeds. This is the first study to provide biomechanical spine movement only in female during running.

As the running speed increased, the participant's hip joint angle changed from flexion to extension at toe-off. Our participants did not display extension of the hip at toe-off probably because they were not accustomed to running on a treadmill. Rendos et al. reported that the maximum hip extension angle during running was $10.9^{\circ 4}$. A positive relationship was observed between hip flexion and lumbar spine extension angles at toe-off when running at 6 and $9 \mathrm{~km} / \mathrm{h}$ but not when running at the $12 \mathrm{~km} / \mathrm{h}$ in this study. The participants were found to extend the spine to compensate for the restricted hip extension at toe-off.

It appears that excessive lumbar extension compensation for restricted hip motion at toe-off could cause low back pain in runners. The repetition of excessive lumbar extension and rotation causes low back pain ${ }^{7}$. In the study, the response to an increase in the running speed was lumbar spine rotation and extension rather than hip extension during the late stance phase. High-speed running can result in mechanical and loading stress to the lumbar spine during this phase. Therefore, coaches and athletic trainers should pay attention to lumbar spine and hip motion of the runners during this phase considering that these factors may predict low back pain.

A limitation of this study was the small number of only female runners. Future studies should longitudinally observe the effects of running in a larger sample of male and female runners with low back pain. Furthermore, the effect of stretching the hip joint and improving the running form or athletic rehabilitation for runners with low back pain should be clarified during running.

In conclusions, an increase in the running speed led to an increase in the rotation angle of the thoracic and lumbar spine as well as an increase in the extension angle of the lumbar spine in healthy runners. Runners extended their lumbar spine to compensate for restricted hip motion at toe-off. 


\section{Presentation at a conference}

We have presented a part of this study in a poster session at the Gait and Clinical Movement Analysis Society (GCMAS) 2017 Meeting, which was held in the Salt Lake City, Utah, from May 23-26, 2017.

\section{Funding}

None.

\section{Conflict of interest}

All authors have no conflicts of interest to disclose.

\section{REFERENCES}

1) Saunders SW, Schache A, Rath D, et al.: Changes in three dimensional lumbo-pelvic kinematics and trunk muscle activity with speed and mode of locomotion. Clin Biomech (Bristol, Avon), 2005, 20: 784-793. [Medline] [CrossRef]

2) Schache AG, Blanch P, Rath D, et al.: Three-dimensional angular kinematics of the lumbar spine and pelvis during running. Hum Mov Sci, 2002, 21: 273-293 [Medline] [CrossRef]

3) Schache AG, Blanch PD, Rath DA, et al.: Intra-subject repeatability of the three dimensional angular kinematics within the lumbo-pelvic-hip complex during running. Gait Posture, 2002, 15: 136-145. [Medline] [CrossRef]

4) Rendos NK, Harrison BC, Dicharry JM, et al.: Sagittal plane kinematics during the transition run in triathletes. J Sci Med Sport, 2013, 16: 259-265. [Medline] [CrossRef]

5) Soler T, Calderón C: The prevalence of spondylolysis in the Spanish elite athlete. Am J Sports Med, 2000, 28: 57-62. [Medline] [CrossRef]

6) Tojima M, Torii S: Changes in lumbopelvic rhythm during trunk extension in adolescent soccer players. Gait Posture, 2017, 52: 72-75. [Medline] [CrossRef]

7) Sairyo K, Katoh S, Sasa T, et al.: Athletes with unilateral spondylolysis are at risk of stress fracture at the contralateral pedicle and pars interarticularis: a clinical and biomechanical study. Am J Sports Med, 2005, 33: 583-590. [Medline] [CrossRef]

8) Burnett DR, Campbell-Kyureghyan NH, Topp RV, et al.: Biomechanics of lower limbs during walking among candidates for total knee arthroplasty with and without low back pain. BioMed Res Int, 2015, 2015: 142562. [Medline] [CrossRef]

9) Alexander EJ, Andriacchi TP: Correcting for deformation in skin-based marker systems. J Biomech, 2001, 34: 355-361. [Medline] [CrossRef]

10) Cappello A, Cappozzo A, Palombara PF, et al.: Multiple anatomical landmark calibration for optimal bone pose estimation. Hum Mov Sci, 1997, 16: 259-274. [CrossRef]

11) Tojima M, Ogata N, Yozu A, et al.: Novel 3-dimensional motion analysis method for measuring the lumbar spine range of motion: repeatability and reliability compared with an electrogoniometer. Spine, 2013, 38: E1327-E1333. [Medline] [CrossRef]

12) Drerup B, Hierholzer E: Movement of the human pelvis and displacement of related anatomical landmarks on the body surface. J Biomech, 1987, 20: 971-977. [Medline] [CrossRef]

13) Gracovetsky S, Newman N, Pawlowsky M, et al.: A database for estimating normal spinal motion derived from noninvasive measurements. Spine, 1995, 20: 1036-1046. [Medline] [CrossRef 